\title{
Biorisk management in studies of highly pathogenic H5N1 viruses
}
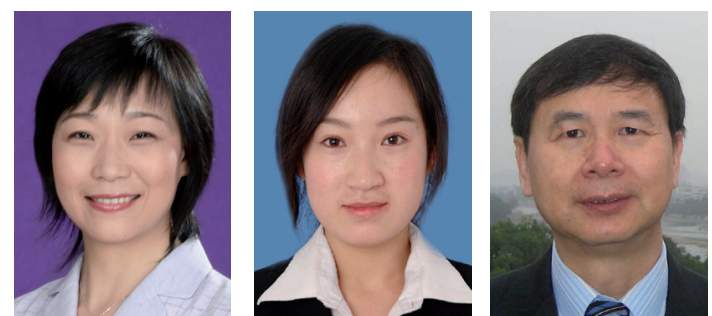

"These mutant viruses

have raised international

controversies over

research safety..."

Lanying Du', Ye Li' \& Shibo Jiang ${ }^{\star 1,2}$

'Lindsley F Kimball Research Institute, New York Blood Center, New York, NY 10065, USA

2Key Lab of Medical Molecular Virology of Ministries of Education \& Health, Shanghai Medical College

\& Institute of Medical Microbiology, Fudan University, Shanghai 200032, China

*Author for correspondence: shibojiang@fudan.edu.cn

Highly pathogenic avian influenza $\mathrm{H} 5 \mathrm{~N} 1$ virus is considered to be the biggest threat for next influenza pandemic, which is reinforced by recent reports of laboratory-generated mutant $\mathrm{H} 5 \mathrm{~N} 1$ virus with airborne transmissibility among ferrets. Thus, an international debate has focused on the biosafety and biorisk issues related to the publications of Ron Fouchier and Yoshihiro Kawaoka's findings in Science and Nature, respectively, recommended by the National Science Advisory Board for Biosecurity (NSABB), a US government advisory panel $[1,2]$. This editorial will briefly describe this event and provide our comments on the biorisk management in studies of highly pathogenic $\mathrm{H} 5 \mathrm{~N} 1$ viruses and other dual-use researches.

A months-long, international debate on the mutant strains of $\mathrm{H} 5 \mathrm{~N} 1$ influenza virus ended after a 2-day meeting held by the NSABB on 29-30 March 2012 on the campus of the US $\mathrm{NIH}$ near Washington, DC [3].

"Many countries with billions of farmed
avians provide few or no influenza
sequences, and surveillance is mostly
based on disease outbreaks or
temporary research projects."

The board has revised their earlier decision on the withholding from publication the key experimental details of two studies related to mutant influenza viruses, and unanimously recommended the full publication of Yoshihiro Kawaoka's revised manuscript submitted to Nature, and advised, in a 12-to-six decision, the communication of the data, methods and conclusions presented in Ron Fouchier's revised manuscript submitted to Science [101]. The board members agreed that the revised versions were described in a clearer way, removing the misunderstanding caused by brevity and tone of the original manuscripts [3]. On 20 April 2012, the US government has formally accepted the NSABB's recommendation to publish these two controversial studies, moving the papers another step closer to publication [102].

In late 2011, Ron Fouchier's group at Erasmus Medical Center in Rotterdam, The Netherlands, created a mutant $\mathrm{H} 5 \mathrm{~N} 1$ virus by introducing five mutations in the virus. Yoshihiro Kawaoka of the School of Veterinary Medicine at the University of Wisconsin-Madison (WI, USA), generated a mutant influenza virus by introducing random mutations into the hemagglutinin (HA) protein of $\mathrm{H} 5 \mathrm{~N} 1$, and combining this mutated HA-encoding gene with other genes from the 2009 pandemic H1N1 virus. Both mutant viruses became more transmissible among mammals, particularly ferrets, an animal species that most closely resembles humans in influenza studies $[1,3,4]$.

As mentioned by Kawaoka at a Royal Society meeting about $\mathrm{H} 5 \mathrm{~N} 1$ research held in London on 03 April 2012, his mutant virus with all four mutations (N158D, N224K, Q226L and T318I) in HA transmitted well among ferrets, showing signs of the virus in the experimental ferrets very quickly. Nevertheless, this mutant virus was nonlethal, and did not kill any of the infected ferrets. The virus did not spread as fast as the swine-origin 2009 pandemic H1N1 strain, nor were they resistant to currently available antiviral agents and vaccines [103]. His intention of making the mutant virus less deadly, as well as the deliberate effort of reducing the risk potentially caused by the mutant virus, lead to the NSABB's unanimous recommendation on the full publication of his

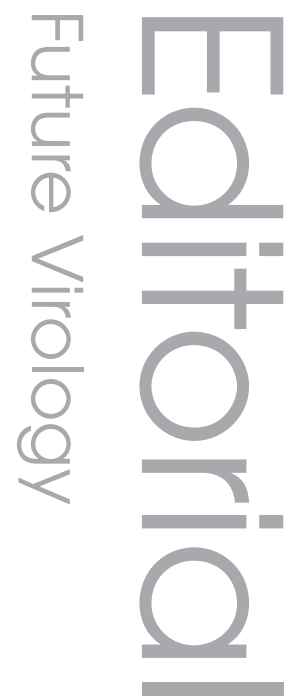

\section{Keywords}

- airborne transmissibility

- biorisk management

- biosafety = biosecurity

- ferret $\approx \mathrm{H} 5 \mathrm{~N} 1$

- hemagglutinin - influenza A

virus $=$ influenza surveillance

- National Science Advisory

Board for Biosecurity

Future $\because$ Medicine 
revised manuscript in Nature [3]. At the same time, Fouchier also revised his manuscript in a clear way to show that the mutant virus was not lethal through the transmission of sneezing and coughing from one ferret to another [104]. Thus, his revised manuscript was recommended by NSABB to be published after appropriate further scientific review and revision.

As far as NSABB is concerned, the unrestricted communication of research information is strongly supported by the board if the information does not pose a significant and immediate risk to public health and safety owing to potential misuse [105]. After all, the benefits of publication of these flu-related research findings, in the eye of NSABB, outweigh its risks. They will provide valuable information for increasing our understanding of the mechanism of virus transmission, since mutations revealed by these studies produced mutant viruses easily transmissible in ferrets [2]. For example, two mutations in Kawaoka's paper, N224K and Q226L, are probably related to host specificity, and one mutation, T318I, may be important for HA stability. The function of the fourth mutation, N158D, needs to be further elucidated $[103,104]$.

\footnotetext{
"These mutant viruses have raised international controversies over research safety, further making the enhancement of current biosafety protocols for emergency situations a practical necessity."
}

The revised manuscripts of the influenza studies will also help to improve our understanding of the specific mutations, enhancing international surveillance and public health and safety. At present, influenza surveillance is lacking. Many countries with billions of farmed avians provide few or no influenza sequences, and surveillance is mostly based on disease outbreaks or temporary research projects [5]. The free sharing of influenza information will enhance, rather than restrict, global surveillance of animal influenza viruses, from which developing countries with endemic $\mathrm{H} 5 \mathrm{~N} 1$ will benefit extensively [3]. This will help with the timely identification of pandemic influenza threats, detection of influenza outbreaks, and in monitoring influenza virus evolution, allowing us to fully understand the factors that cause virus spread [5].

At the same time, NSABB members also expressed concerns regarding dual-use research, with their recommendations being informed by the newly released US Government Issues Policy on Oversight of Life Science Dual Use Research of Concern. This new policy emphasizes the significance of addressing dual-use concerns in the evaluation of ongoing and future research on $\mathrm{H} 5 \mathrm{~N} 1$ influenza virus, minimizing the risk of misuse or accidental transmission of avian influenza virus while fully preserving the benefits of life science research. In the policy, the highly pathogenic avian influenza virus is on the top list of the agents and toxins that pose the greatest risk of deliberate misuse [106].

In view of the high transmissibility of laboratory-generated mutant influenza virus, a reasonable management of biorisks potentially caused by highly pathogenic $\mathrm{H} 5 \mathrm{~N} 1$ virus is particularly necessary. Currently, a series of biosafety and biosecurity protocols have been established and performed for handling and manipulating highly pathogenic $\mathrm{H} 5 \mathrm{~N} 1$ virus. However, there is still some room for improvement in minimizing potential risks. It is strongly recommended that laboratory safety-related facilities and procedures be continually monitored and enhanced, and that rapid containment steps be intensified. In addition, however, there is always a significant possibility of naturally generating reassortant influenza viruses with the potential for human-to-human transmission. Therefore, it is strongly suggested that comprehensive biosafety and biosecurity strategies be fully implemented, and global surveillance be extensively monitored at all times. Although the laboratory-created $\mathrm{H} 5 \mathrm{~N} 1$ mutants are less lethal, as indicated in the revised manuscripts, these mutant $\mathrm{H} 5 \mathrm{~N} 1$ viruses with high transmissibility in mammals should be handled at the highest biocontainment level: BSL4 [6]. These mutant viruses have raised international controversies over research safety, further making the enhancement of current biosafety protocols for emergency situations a practical necessity.

Financial \& competing interests disclosure

The authors have no relevant affiliations or financial involvement with any organization or entity with a financial interest in or financial conflict with the subject matter or materials discussed in the manuscript. This includes employment, consultancies, honoraria, stock ownership or options, expert testimony, grants or patents received or pending, or royalties.

No writing assistance was utilized in the production of this manuscript. 


\section{References}

1. Fouchier RA, Garcia-Sastre A, Kawaoka Y et al. Pause on avian flu transmission research. Science 335(6067), 400-401 (2012).

2. Kawaoka Y. H5N1: flu transmission work is urgent. Nature 482(7384), 155 (2012).

3. Cohen J, Malakoff D. Avian influenza. On second thought, flu papers get go-ahead. Science 336(6077), 19-20 (2012).

4. Enserink M. Biosecurity. In the eye of the storm, two rivals, two strategies. Science 335(6064), 21 (2012).

5. Butler D. Flu surveillance lacking. Nature 483(7391), 520-522 (2012).

6. Imperiale MJ, Hanna MG III. Biosafety considerations of mammalian-transmissible H5N1 influenza. MBio. 3(2), e00043-12 (2012).

\section{Websites}

101. National Science Advisory Board for Biosecurity findings and recommendations. http://oba.od.nih.gov/oba/biosecurity/ PDF/03302012_NSABB_Recommendations. pdf

102. U.S. accepts NSABB recommendation to publish $\mathrm{H} 5 \mathrm{~N} 1$ flu papers. http://news.sciencemag.org/ scienceinsider/2012/04/breaking-us-acceptsrecommendation.html? ref=hp

103. Mutations behind flu spread revealed. www.nature.com/news/mutations-behind-fluspread-revealed-1.10394?WT.ec_ id $=$ NEWS -20120410

104. Free to speak, Kawaoka reveals flu details while Fouchier stays mum. http://news.sciencemag.org/ scienceinsider/2012/04/free-to-speakkawaoka-reveals-fl.html

105. NSABB policy update: manuscripts on transmissibility of $\mathrm{A} / \mathrm{H} 5 \mathrm{~N} 1$ influenza virus. http://centerforvaccineethicsandpolicy. wordpress.com/2012/04/07/nsabb-policyupdate-manuscripts-on-transmissibility-ofah5n1-influenza-virus

106. United States Government Policy for Oversight of Life Sciences Dual Research of Concern.

http://oba.od.nih.gov/oba/biosecurity/PDF/ United_States_Government_Policy_for_ Oversight_of_DURC_FINAL_ version_032812.pdf 